Revue d'histoire de l'enfance « irrégulière »

Le Temps de I'histoire

15 | 2013

Enfances déplacées. (II) en temps de guerre

\title{
(Lectures de) Ceci n'est pas une prison . Histoire d'une institution pour garçons délinquants en Suisse romande (1805-1846-1987)
}

Jacques Bourquin

\author{
(2) OpenEdition \\ Journals \\ Édition électronique \\ URL : http://journals.openedition.org/rhei/3553 \\ DOI : 10.4000/rhei.3553 \\ ISSN : 1777-540X \\ Éditeur \\ Presses universitaires de Rennes
}

Édition imprimée

Date de publication : 30 octobre 2013

Pagination : 224-227

ISBN : 978-2-7535-2896-3

ISSN : 1287-2431

Référence électronique

Jacques Bourquin, «(Lectures de) Ceci n'est pas une prison. Histoire d'une institution pour garçons délinquants en Suisse romande (1805-1846-1987) », Revue d'histoire de l'enfance « irrégulière » [En ligne], 15 | 2013, mis en ligne le 30 octobre 2013, consulté le 22 septembre 2020. URL : http:// journals.openedition.org/rhei/3553; DOI : https://doi.org/10.4000/rhei.3553

Ce document a été généré automatiquement le 22 septembre 2020

(C) PUR 


\title{
(Lectures de) Ceci n'est pas une prison . Histoire d'une institution pour garçons délinquants en Suisse romande (1805-1846-1987)
}

\author{
Jacques Bourquin
}

\section{RÉFÉRENCE}

Lausanne, Éditions Antipodes, collection « Histoire », 438 p. ISBN 9782889010738

1 Voici un ouvrage qui nous vient de Suisse romande. Geneviève Heller, historienne à la Haute école de travail social à Lausanne, nous présente une belle recherche monographique sur la maison d'éducation de Vennes, dans le canton de Vaud.

Cette institution, à l'histoire presque bicentenaire, qui, jusqu'à ces dernières années reçut des mineurs placés par les autorités judiciaires et civiles du canton de Vaud, fut au $\mathrm{XIX}^{\mathrm{e}}$ siècle une maison de discipline sur le modèle des colonies agricoles puis beaucoup plus tard, au début $\mathrm{du} \mathrm{xx}^{\mathrm{e}}$ siècle, une école de réforme. C'est une longue histoire qui s'apparente à celle des maisons de correction et de ce que l'on appellera aussi bagnes d'enfants en France. Une institution essentiellement répressive dont les quelques tentatives de réforme en 1930, restèrent très aléatoires. En 1941, Vennes prend le nom de maison d'éducation, annonçant le Code pénal suisse pour mineurs de 1942 qui privilégie la référence éducative, atténue le volet répressif sans toutefois faire disparaître la détention. Trois organismes, qui viennent d'être créés, apparaissent comme les partenaires de cette nouvelle école : la chambre pénale des mineurs, mais aussi l'office cantonal des mineurs et l'office médico-psychologique vaudois. Il y a une réelle volonté de la part du directeur, venu du scoutisme, de casser la référence uniquement pénale. Ces tentatives de réforme resteront toutefois tributaires du climat carcéral, de l'architecture et des réticences des personnels pénitentiaires. 
3 Il faut attendre le début des années 1950, pour que la maison d'éducation de Vennes (MEV) évolue dans un registre éducatif. Ceci est lié à l'arrivée d'un nouveau directeur qui apparaît, selon Geneviève Heller, comme "la figure emblématique de la MEV ». L'architecture disciplinaire est abandonnée, on supprime les chemins de ronde, les barreaux des fenêtres... Arrivent les premiers éducateurs, formés au centre de formation pour l'enfance et l'adolescence inadaptées de Lausanne. C'est une période constructive, innovante, le nouveau directeur se réfère aux théories de l'éducation nouvelle, et initie aux pédagogies actives. Une grande importance est accordée à la formation professionnelle, aux loisirs, l'institution s'ouvre sur l'extérieur, le régime de la semi-liberté est introduit. Cette période, qui se poursuit dans les années 1960, s'inscrit pleinement dans un mouvement international relatif au placement institutionnel et à l'éducation des mineurs délinquants. Par l'intermédiaire du juge des enfants suisse, M. Veillard, Vennes est en lien avec Jean Chazal, un des pionniers français de la justice des mineurs et Henri Joubrel, président de l'Association internationale des éducateurs de jeunes inadaptés. Vennes, qui reçoit des adolescents à partir de 14 ans, développe l'observation psychiatrique et l'orientation professionnelle, devient une institution modèle qui modifie son image auprès de l'opinion publique.

4 À cette période dynamique succède une autre plus problématique au cours des années 1970. On reproche au directeur nommé en 1967, un ancien éducateur de Vennes, de ne pas suffisamment s'occuper des problèmes pédagogiques et psychologiques, il est en revanche un très bon administrateur. L'institution est alors confrontée à des problèmes de drogue et à un certain désarroi des jeunes. Tout ceci n'est pas sans lien, précise l'auteure, avec la crise contestataire de la société des années 1970 et ses questionnements autour du travail social. À Vennes, l'orientation professionnelle a surtout été développée au détriment d'autres initiatives pédagogiques. Certains éducateurs et le sous-directeur démissionnent. Entre 1977 et 1979, se crée, sur le modèle des groupes d'information sur les prisons initiés par Michel Foucault en France, un groupe d'information sur Vennes. Y participent des professionnels de l'action sociale, des éducateurs, des témoignages de certains jeunes de la MEV sont sollicités. Un dossier est publié en 1978: "L'antichambre de la taule.» Il y a derrière cette campagne l'expression d'une forte réticence à l'égard du placement institutionnel qui ne ferait qu'aggraver le problème des jeunes, la drogue serait l'aboutissement du climat répressif qui règne à Vennes; ces critiques sont en phase avec les courants de désinstitutionalisation des années 1970 en France, en Belgique, avec le souci du développement du milieu ouvert, et du maintien dans le milieu familial. On reproche au directeur de ne pas avoir de ligne éducative, il est déplacé. Une commission présidée par M. Pahud, directeur de l'École de formation d'éducateurs de Lausanne, prévoit la suppression du gros internat de Vennes (une cinquantaine d'adolescents). Un établissement ouvre en 1981 avec de petites unités d'internats pour six jeunes, bénéficiant chacune d'une grande autonomie. Un centre d'accueil mixte pour de courts séjours est créé, on insiste sur la nécessité de renforcer l'individuation de la relation avec le jeune, en évitant comme par le passé, la concentration de jeunes trop difficiles. Le terme de maison d'éducation est abandonné, trop connoté à une histoire antérieure. Le nouvel établissement prend le nom de centre cantonal de Vennes (CCV), la priorité est accordée à la formation professionnelle de jeunes présentant des difficultés de comportement et de caractère. 
5 En 1987, le CCV devient le COFOP (Centre d'orientation et de formation professionnelle); le nom de Vennes disparaît sans doute, précise Geneviève Heller, " pour couper le lien avec la renommée négative attachée au passé de l'institution ».

6 En 2008, le COFOP, est reconnu en tant qu'école des métiers cantonale pour les jeunes en difficulté psycho-sociale. Concernant les jeunes délinquants, le grand conseil vaudois prévoit, pour 2013, une maison de détention de 56 places à Palezieux. Dans la préface, M. Pahud conclut, non sans aménité : « Il arrive que l'histoire se répète. »

7 Dans la seconde partie de son ouvrage, G. Heller, qui a pu consulter de nombreuses archives déposées à partir de 1993, aborde d'une manière concrète plusieurs thèmes qui traversent l'histoire de Vennes : l'architecture, les élèves, le personnel éducatif, les punitions, la formation professionnelle, les loisirs, l'observation, qui illustrent avec richesse l'histoire si contrastée de cette institution. 